\title{
A Method and Equipment for Continuously Testing the Permeability Coefficient of Rock and Soil Layers
}

\author{
Wei Chen ${ }^{1},{ }^{1}$ Datian Cui, ${ }^{2}$ Meng Xu, ${ }^{3}$ and Rongchao Xu ${ }^{1}{ }^{1}$ \\ ${ }^{1}$ College of Geosciences and Engineering, North China University of Water Resources and Electric Power, \\ Zhengzhou 450045, China \\ ${ }^{2}$ School of Materials Science and Engineering, North China University of Water Resources and Electric Power, \\ Zhengzhou 450045, China \\ ${ }^{3}$ College of Geology and Info-Physics Engineering, Central South University, Changsha 410083, China
}

Correspondence should be addressed to Rongchao Xu; rcxirsm@126.com

Received 4 November 2020; Revised 30 November 2020; Accepted 8 December 2020; Published 24 December 2020

Academic Editor: Zhi Cheng Tang

Copyright (c) 2020 Wei Chen et al. This is an open access article distributed under the Creative Commons Attribution License, which permits unrestricted use, distribution, and reproduction in any medium, provided the original work is properly cited.

The water pressure test and steady-flow pumping test are still commonly used for measuring the permeability coefficient of rock and soil strata. Limited by the fact that the average value of the permeability coefficient could be obtained only by this testing method, the accuracy of the experimental results of the permeability coefficient for special rock and soil strata is not good. Therefore, a new on-site testing method and equipment for continuously measuring the permeability coefficient of rock and soil strata is studied in this paper. The method is suitable for water pressure testing in borehole and the steady-flow pumping test. The technical proposal is when the pumping test or water pressure test is carried out, the final water penetration will tend to be a stable value, and then, the high-precision current meter probe will be placed at the bottom of the pumping test hole or water pressure test hole. For the pumping test, the current meter will be lifted uniformly from the bottom of the borehole testing section to the stable water level. Meanwhile, the flow rate of a differential zone of the tested section is continuously detected. For the water pressure test, the current meter will be lifted uniformly from the bottom of the borehole test section to the top of the borehole test section, and the flow rate of the differential section will be continuously detected. Through data analysis and processing, not only the average permeability coefficient of the detected sections can be obtained but also the permeability coefficient of the differential section of the rock and soil stratum can be calculated, respectively. Furthermore, the corresponding relationship between the permeability coefficient and the detected location can be obtained. In view of the abovementioned reasons, the leaking point, the specific position, and the leakage quantity of the detected section could be found out accurately, which will improve the accuracy of the testing results obviously.

\section{Introduction}

The water pressure test and pumping test are common test methods for measuring the permeability coefficient of rock and soil layers [1]. The water pressure test is to isolate a certain length of the borehole test section with special waterstop equipment and then use a fixed water pressure to pressurize water into this section of borehole; water seeps into the rock mass through the cracks around the borehole wall, and eventually, the amount of water seeped will tend to a stable value; according to the water pressure, the length of the test section, and the stable amount of water seeped into the rock mass, the permeability coefficient of rock mass can be calculated. The stable flow pumping test means that the flow rate and water level are relatively stable in a certain period of time. The permeability coefficient of rock and soil can be calculated by using various theoretical formulas of groundwater flow. However, the two methods have the following disadvantages [2-4]: (1) At present, the permeability coefficient obtained by the water pressure test and pumping test is the average value of the rock and soil stratum in a test section. The permeability coefficient of a differential section of the rock and soil stratum in the test section cannot be calculated, the corresponding relationship between the 
permeability coefficient and test section cannot be obtained, and the specific location and leakage amount of the leakage point and section cannot be accurately identified. (2) The theoretical conditions do not agree with the actual geological conditions. The method of the pressure water test and steady-flow pumping test considers that the seepage water in the test section only distributes in the rock mass between the upper and lower ends of the test section and the two parallel planes perpendicular to the test section. There is no hydraulic connection between the test sections and the bottom of the hole. In fact, they have complex hydraulic connections. In order to overcome the abovementioned problems, the method and equipment of continuous detection of the permeability coefficient of the rock and soil stratum can be used. This method and equipment can not only detect the average permeability coefficient of the test section but also accurately detect the permeability coefficient along the differential section of the rock and soil stratum along the test section, obtain the corresponding relationship between the permeability coefficient and the test section, and accurately find out the leakage point. The specific location and leakage amount of the segment effectively improve the accuracy of the test results.

\section{Working Principle}

2.1. Differential Water Pressure Test. The purpose of this scheme is to provide a method of the single-stage differential water pressure test with a high sensitivity and large-range ratio anemometer, as shown in Figure 1. The testing program is to drill the test hole in stages. After the single hole is finished, the hole is washed and the orifice tube is placed, the probe of current meter is put into the bottom of the hole, the single hole orifice is sealed, and the water is supplied to the hole to achieve the specified value. When the water flow in the hole is stable, the stepper motor works and sends the probe slowly and uniformly to the top of the single hole along the axis of the test section from the bottom to top. The probe can measure the velocity of flow at each point along the borehole axis and convert it into flow. The flow of a differential hole section is equal to the difference between the flow of the upper and lower sections of the hole section. The length of the differential test section is measured by using a stepping motor. The pressure is derived from the measured value of the pressure sensor installed at the hole mouth and the static position of groundwater. The permeability of the hole section is calculated according to formula (1) of the pressure water test [5-7]. The absorption rate is calculated, and the distribution map of the test data of the differential pore section along the hole depth is drawn.

$$
\Delta q=\frac{\Delta Q}{P \Delta L},
$$

where $\Delta q$ is the absorption rate of the differential section, $\mathrm{Lu}$; $\Delta Q$ is the water quantity pressed into rock mass of the differential section, $\mathrm{m}^{3} ; \mathrm{P}$ is the test pressure; and $\Delta L$ is the test length of the differential section, $\mathrm{m}$.

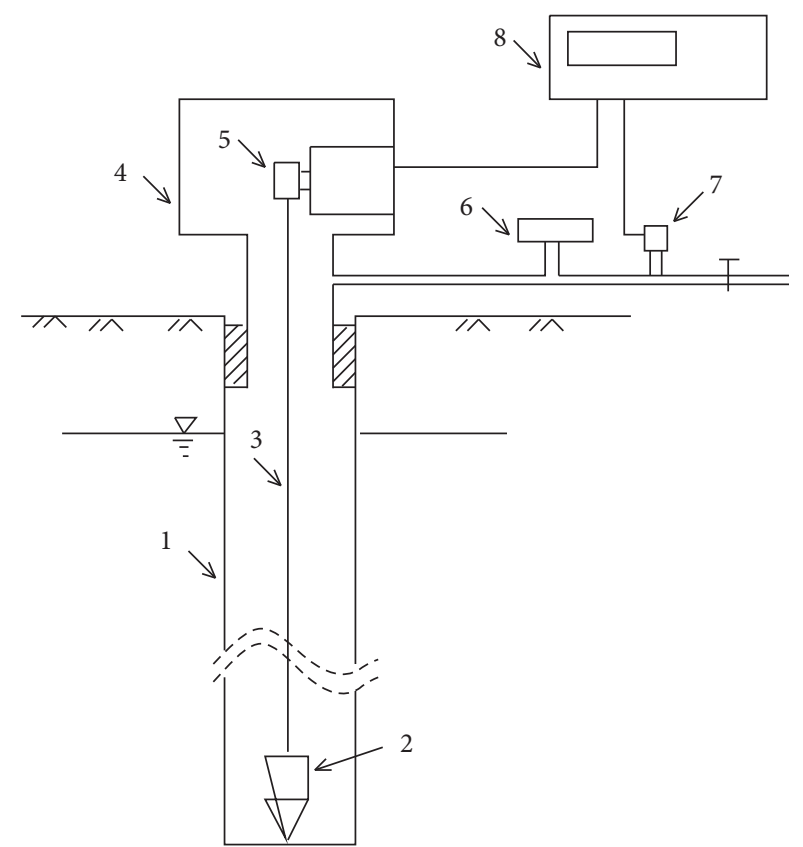

FIgURE 1: Layout plan of the differential water pressure test scheme. 1- drill hole; 2 - turbine current meter; 3 - electric cable; 4- sealing device; 5 - stepper motor; 6 - water supply device; 7 - pressure sensor; and 8-computer.

2.2. Differential Steady-Flow Pumping Test. The steady-flow pumping test is to drill a pumping test hole and several water level observation holes at the designed position, respectively. A pumping system is used to pump water from the pumping test hole to form a stable flow, forming a depressing funnelshaped groundwater surface centered on the pumping test hole; as shown in Figure 2, when the water flow is assumed to flow horizontally, the cross section of seepage through the hole should be a series of concentric cylindrical surfaces. The pumping quantity $Q$ is measured, and the distance between the observation hole and the axis of the pumping test hole are $r 1$ and $r 2$, respectively. The average $K$ value and differential $\Delta K$ value of the soil layer can be obtained by Darcy's law $[1,8,9]$.

Now, a cross section is taken around the axis of the pumping test hole. The distance between the cross section and the center of the pumping test hole is $r$, and the height of the water surface is $h$. Then, the cross section area A is

$$
A=2 \pi r h \text {, }
$$

where $A$ is the cross-section area, $\mathrm{m}^{2} ; r$ is the distance between the cross section and the center of the pumping test hole, $\mathrm{m}$; and $\mathrm{h}$ is the water surface height, $\mathrm{m}$.

Assuming that the hydraulic gradient is constant and equal to the gradient of the groundwater level line at this point,

$$
i=\frac{\mathrm{d} h}{\mathrm{~d} r},
$$

where $i$ is the hydraulic gradient at the cross section. 


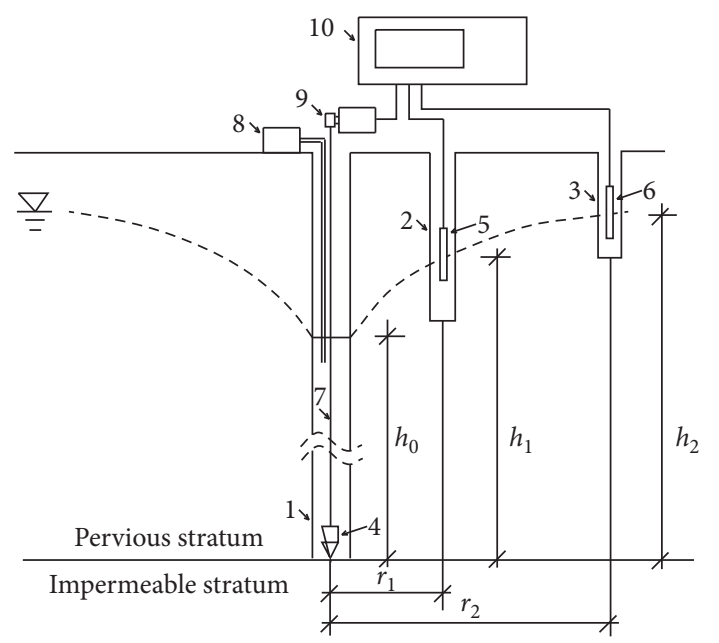

FIGURE 2: Schematic diagram of continuous detection by the steady-flow pumping test. 1- pumping test hole; 2 - observation borehole I; 3- observation borehole II; 4- turbine current meter; 5water level monitor (1); 6- water level monitor (2); 7- electric cable; 8- pumping device; 9- stepper motor; and 10- computer.

According to Darcy's law, the amount of water pumped from the well per unit time is

$$
Q^{\prime}=A k i=2 \pi r h \cdot k \frac{\mathrm{d} h}{\mathrm{~d} r},
$$

where $Q$ is the amount of water pumped from the pumping test hole per unit time, $\mathrm{m}^{3} ; k$ is the permeability coefficient, $\mathrm{cm} / \mathrm{s}$.

The integral equation (3) is

$$
Q^{\prime} \int_{r 1}^{r 2} \frac{\mathrm{d} r}{r}=2 \pi k \int_{h 1}^{h 2} h \mathrm{~d} h .
$$

Then,

$$
\begin{gathered}
k=\frac{Q^{\prime}}{\pi} \frac{\ln \left(r_{2} / r_{1}\right)}{\left(h_{2}^{2}-h_{1}^{2}\right)}, \\
\Delta k=\frac{h_{0}}{\Delta h} \frac{\Delta Q^{\prime}}{\pi} \frac{\ln \left(r_{2} / r_{1}\right)}{\left(h_{2}^{3}-h_{1}^{2}\right)},
\end{gathered}
$$

where $\Delta k$ is the permeability coefficient of a differential section, $\mathrm{cm} / \mathrm{s} ; \Delta Q^{\prime}$ is the amount of water drawn from pumping test hole of the differential section in the unit time, $\mathrm{m}^{3}$.

A probe of the current meter is placed at the bottom of the pumping test hole and lifted from the bottom of the test hole to the stable water level uniformly. It continuously detects the flow of the differential section. Two water level monitors are used to detect the flow from the bottom of the hole to the stable water level test section, and two water level monitors, which are, respectively, placed in observation hole I and II, are used to check the water level $h_{1}$ and $h_{2}$; By computer system analysis and processing, the distribution of the permeability coefficient of the rock and soil stratum along the depth of the pumping test hole can be obtained.

\section{Hardware Design}

3.1. Hardware Composition Design. The structure of the system is shown in Figure 3 [10-16]. The system consists of four sensors and a host computer. The host computer is mainly composed of an 80C196 single-chip computer system, input channel (sensor, interface circuit, and keyboard), output channel (monitor, printer, and data transponder), and so on. The sensors include a current meter probe, water level monitor, displacement sensor, and pressure sensor. Among them, the current meter probe measures the flow velocity along the axis of the borehole and converts it into an electric pulse signal which passes through the signal line in the cable and the photoelectric isolator and sends it to the microcomputer system; the pressure sensor measures the water pressure, and the water level monitor measures the water level of the observation hole and converts it into an analog signal which passes through the signal line and photoelectric isolation and sends it to the microcomputer system. The computer processes and analyses the abovementioned signals to get the distribution of absorption rate or permeability coefficient of rock and soil along the borehole range and displays and prints them.

3.2. Interface between the Sensor and MCU. The analog sensor signal is a $4-20 \mathrm{~mA} \mathrm{DC}$ current signal. The analog signal can be directly connected with the A/D conversion circuit integrated in the 80C196 single-chip computer through the interface. Its interface is composed of an isolator, I/V converter, low-pass filter, protection circuit, and reference voltage. The analog current signal of $4-20 \mathrm{~mA}$ is input into the interface circuit through an electromagnetic isolator. It is converted into $1-5 \mathrm{~V} \mathrm{DC}$ voltage by the I/V converter. After the interference signal is removed by using the low-pass filter, it is fed to the A/D port of the single-chip computer [11-14].

The pulse sensor is a high-frequency pulse signal, which is transformed into a regular negative-tip pulse signal by phase-sensitive rectification, coupled by a photoelectric isolator, differential circuit, and monostable trigger, and then transformed into a standard rectangular wave. The $80 \mathrm{C} 196$ microcontroller reads the corresponding port data at the set time interval [11-14].

\section{Software Design}

This software adopts $80 \mathrm{C} 196 \mathrm{~KB}$ single-chip computer $c$ language for modular structure program design and sets dozens of subprograms. The main program part of the flow chart is shown in Figure 4 [12-16]. The software can be divided into the following main modules by function. (1) data acquisition module-completing the flow rate data at the flow meter and the data of the test hole depth provided by the servo motor and the collection of various signs; (2) test module-completing the test according to the water pressure test and pumping test procedures; (3) data processing module-calculating the flow distribution data along the axis of the test hole; process and analyze the data according to 


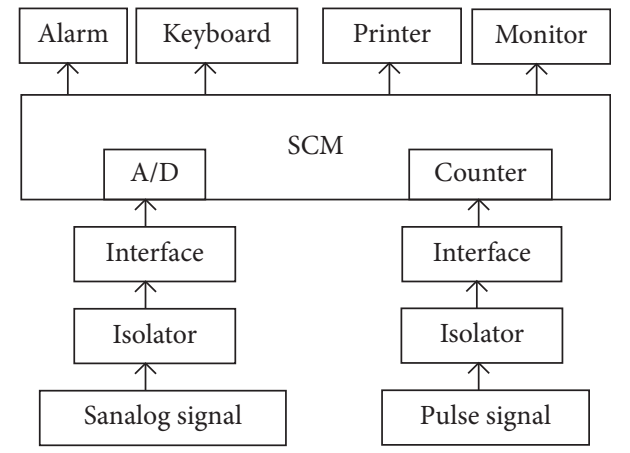

Figure 3: Host computer schematic diagram of continuous detection by the steady-flow pumping test.

Darcy's law and related calculation formulas, and obtain the permeability coefficient along the axis of the test hole; and (4) data printing module- the curves and tables required for printing.

\section{Simulation Test and Discussion}

The porous pumping test is carried out at a certain site. The pumping hole belongs to the diving integrity hole. The pumping hole depth is 15.2 meters, the groundwater level is 2 meters deep, and the water level drops 3.2 meters after pumping. The distance between observation hole I and II from the center of the pumping test hole is observed, $r 1$ and $r 2$ are $4.3 \mathrm{~m}$ and $10 \mathrm{~m}$, respectively, and the water levels in observation hole I and II are $12.45 \mathrm{~m}$ and $12.72 \mathrm{~m}$, respectively, and the permeability coefficient calculated according to formula (6) is $5.23 \mathrm{~m} / \mathrm{d}$. Then, the current meter probe is uniformly raised upward from the bottom of the pumping test hole ( $15.2 \mathrm{~m}$ below the ground) to the stable water level (5.2 $\mathrm{m}$ below the ground). After data processing and analysis, the distribution curves of pumping capacity and permeability coefficient with pumping hole depth are obtained, as shown in Figure 5. The test results show that (1) the permeability coefficient is not a fixed value with the change of the hole depth, but fluctuates within a large range; the minimum is $0.48 \mathrm{~m} / \mathrm{d}$ and the maximum is $24.66 \mathrm{~m} / \mathrm{d}$; (2) the section with small permeability coefficient can be judged as an impervious section, and the section with large permeability coefficient can be judged as a leakage point or section, such as points A, B, C, and D in Figure 5; and (3) the corresponding relationship between the permeability coefficient and test section is obtained, and the specific location and leakage amount of the leakage point and section are found accurately, which effectively improves the accuracy of test results.

The water pressure test was carried out at a certain fractured rock mass site. The depth of the test hole was $15 \mathrm{~m}$, the depth of the pressurized water test section was $5-15 \mathrm{~m}$, the test pressure was $1.0 \mathrm{MPa}$, and the water flow was $31.6 \mathrm{~L} /$ $\mathrm{min}$. The absorption rate is $6.32 \mathrm{Lu}$ according to formula (1). Then, the current meter probe is uniformly raised upward from the bottom of the water pressure test hole $(15.0 \mathrm{~m}$ below the ground) to the top of the water pressure test hole ( $5.0 \mathrm{~m}$ below the ground). After data processing and

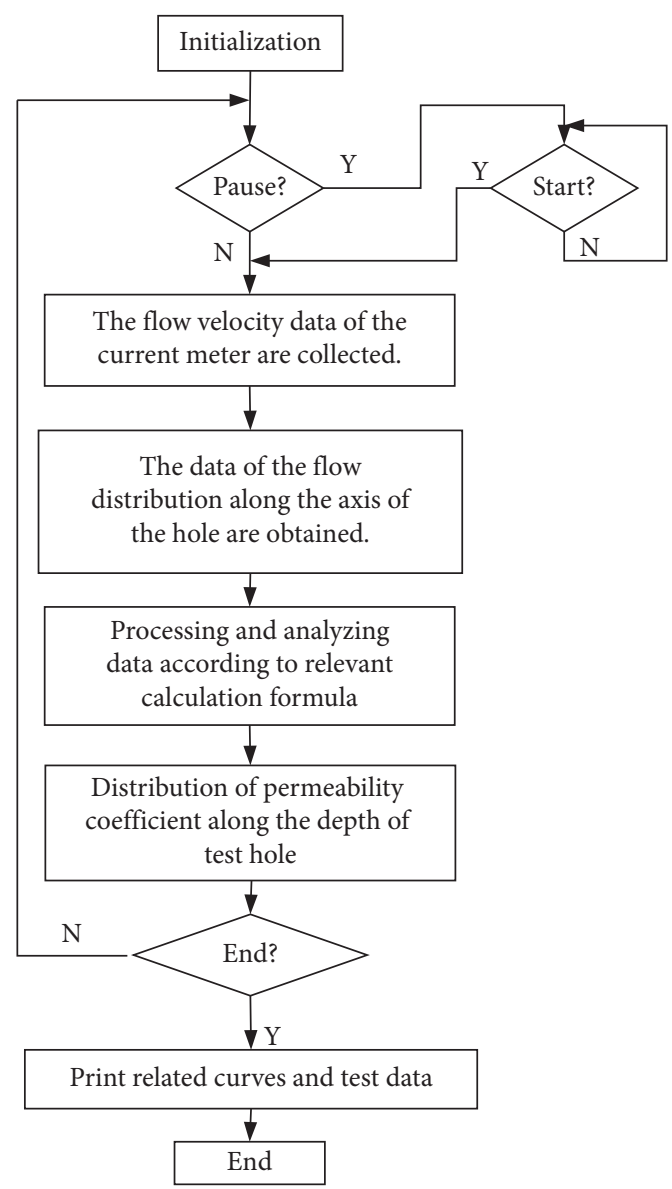

FIGURE 4: Main program flowchart.

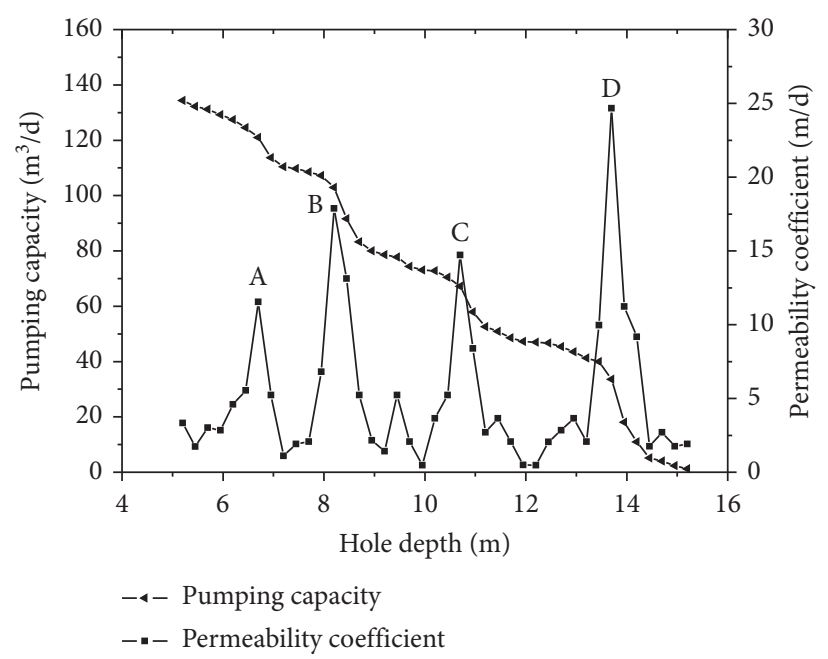

FIgURE 5: Distribution curves of the pumping capacity and permeation coefficient with the pumping hole depth.

analysis, the distribution curves of pressurized water flow and absorption rate with water pressure test hole depth are obtained, as shown in Figure 6. The test results show that (1) the absorption rate is not a fixed value with the change of the hole depth, but fluctuates within a large range, the minimum is $1.32 \mathrm{Lu}$, and the maximum is $43.32 \mathrm{Lu}$; (2) the section with 


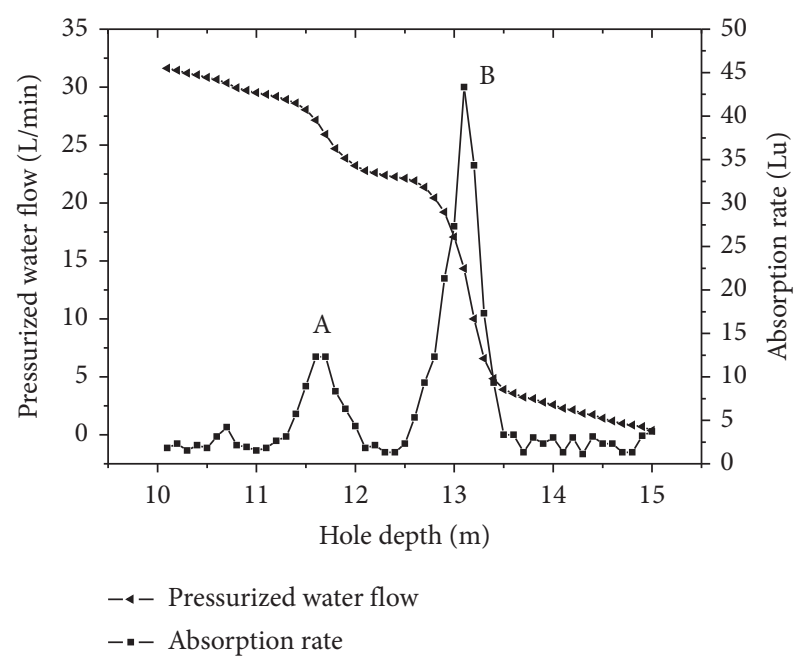

FIGURE 6: Distribution curves of pressurized water flow and absorption rate with the pumping hole depth.

small absorption rate can be judged as an impervious section, and the section with large absorption rate can be judged as a leakage point or section, such as points $A$ and $B$ in Figure 6; and (3) the corresponding relationship between the absorption rate and test section is obtained, and the specific location and leakage amount of the leakage point and section are found accurately, which effectively improves the accuracy of test results.

\section{Conclusions}

(1) This paper studies a method and equipment for continuously detecting the permeability coefficient of the rock soil layer. This method is suitable for the drilling water pressure test and steady-flow pumping test and introduces the test principle, equipment hardware, and software design.

(2) The method and equipment can continuously detect the flow of the differential section of rock and soil strata in the test section. After the data analysis and processing, the method and the device can not only obtain the average permeability coefficient of the test section but also get the microsegment permeability coefficient of the test section; meanwhile, the corresponding relationship between the permeability coefficient and the test section is obtained, the leakage point, the specific position of the section, and the leakage amount are accurately found, and the precision of the test result is effectively improved.

(3) The test results show that (1) the permeability coefficient or absorption rate varies with the depth of the hole, sometimes not a fixed value, but fluctuates within a large range; (2) the section with small permeability or absorption rate can be judged as impervious, while the section with large permeability coefficient or absorption rate can be judged as a leakage point and section; and (3) according to the corresponding relationship between permeability or absorption rate and the test section, the leakage point, the specific position of the section, and the leakage amount can be accurately found.

\section{Data Availability}

The figure data used to support the findings of this study are included within the article.

\section{Conflicts of Interest}

The authors declare that they have no conflicts of interest.

\section{References}

[1] N. Men, Y. W. Sun, and J. S. Bo, "Study of permeability coefficient in pumping test on steady flow in completely penetrating well," Advanced Materials Research, vol. 379, pp. 362-365, 2012.

[2] S. R. Paiva, L. A. Lima, and F. Maria Raquel, "Analysis on determination of hydraulic conductivity for steady flow in fully pumping tests," Railway Investigation \& Surveying, vol. 83, no. 4, pp. 1165-1170, 2010.

[3] O. Banton and L. M. Bangoy, "A new method to determine storage coefficient from pumping test recovery data," Groundwater, vol. 34, no. 5, pp. 772-777, 2010.

[4] Q. Fan, Z. Wang, J. Xu, M. Zhou, Q. Jiang, and G. Li, "Study on deformation and control measures of columnar jointed basalt for baihetan super-high arch dam foundation," Rock Mechanics and Rock Engineering, vol. 51, no. 8, pp. 2569-2595, 2018.

[5] Q. Wang and H. Zhan, "The effect of intra-wellbore head losses in a vertical well," Journal of Hydrology, vol. 548, pp. 333-341, 2017.

[6] Q. Wang and H. Zhan, "Intrawellbore kinematic and frictional losses in a horizontal well in a bounded confined aquifer," Water Resources Research, vol. 53, no. 1, pp. 127-141, 2017.

[7] H. P. Patra, S. K. Adhikari, and S. Kunar, "Aquifer parameters, pumping test and the yield," Springer Hydrogeology, pp. 159-181, 2016.

[8] X. Wang and A. Xiong, Advanced Fluid Mechanics, Huazhong University of Science and Technology Press, Wuhan, China, 2003.

[9] W. Li, A. Englert, and H. Vereecken, "Inference of 3-D hydraulic conductivity from flowmeter and pumping-test data," in Proceedings of the AGU Fall Meeting Abstracts, San Francisco, CA, USA, May 2007.

[10] F. Kohlbeck and A. Alvarez, "A method to determine the formation constants of leaky aquifers, and its application to pumping test data," Groundwater, vol. 29, no. 3, pp. 425-429, 2010.

[11] M. Xu, P. Zhen-Bin, and C. Xun, "Design of detection system for differential water pressure," Transducer \& Microsystem Technologies, vol. 30, no. 1, pp. 76-78, 2011.

[12] Q. Fan, C. Huang, and X. Jiang, "Intelligent grouting control method and system for hydropower engineering," Journal of Hydraulic Engineering, 2018.

[13] Y. Fan and X. F. Wu, "The design of intelligent pressure detection and alarm system," Advanced Materials Research, vol. 961, no. 4, 2014.

[14] M. Xu, The Development and Research of a New Intelligent Grouting and Pressurized Water Detection System, Central South University, Changsha, China, 2010. 
[15] C. Wei, M. Xu, and J.-Q. He, "Study of grouting on-line detecting system based on SCM," Instrument Technique \& Sensor, 2010.

[16] W. Chao, L. Xu, and M. Xu, "Design and experimentation of grouting pressure automatic control system on PLC," Journal of Central South University, vol. 44, no. 10, pp. 4055-4062, 2013. 